\title{
Modulators of arginine metabolism support cancer
} immunosurveillance

\author{
Giusy Capuano ${ }^{1}$, Nicolò Rigamonti ${ }^{1}{ }^{1}$, , Matteo Grioni ${ }^{1}$, Massimo Freschi ${ }^{3}$ and \\ Matteo Bellone*1
}

Address: ${ }^{1}$ Cancer Immunotherapy and Gene Therapy Program, Istituto Scientifico San Raffaele, Via Olgettina 58, 20132, Milan, Italy, ${ }^{2}$ Università Vita-Salute San Raffaele, Via Olgettina 58, 20132, Milan, Italy and ${ }^{3}$ Unità Operativa Anatomia Patologica, Istituto Scientifico San Raffaele, Via Olgettina 58, 20132, Milan, Italy

Email: Giusy Capuano - giusy_capuano@hotmail.com; Nicolò Rigamonti - rigamonti.nicolo@hsr.it; Matteo Grioni - grioni.matteo@hsr.it; Massimo Freschi - freschi.massimo@hsr.it; Matteo Bellone* - bellone.matteo@hsr.it

* Corresponding author

Published: 9 January 2009

BMC Immunology 2009, 10:1 doi:10.1 186/147|-2172-10-1
Received: 10 April 2008

Accepted: 9 January 2009

This article is available from: http://www.biomedcentral.com/I47I-2172/10/I

(C) 2009 Capuano et al; licensee BioMed Central Ltd.

This is an Open Access article distributed under the terms of the Creative Commons Attribution License (http://creativecommons.org/licenses/by/2.0), which permits unrestricted use, distribution, and reproduction in any medium, provided the original work is properly cited.

\begin{abstract}
Background: Tumor-associated accrual of myeloid derived suppressor cells (MDSC) in the blood, lymphoid organs and tumor tissues may lead to perturbation of the arginine metabolism and impairment of the endogenous antitumor immunity. The objective of this study was to evaluate whether accumulation of MDSC occurred in Th2 prone BALB/c and ThI biased C57BL/6 mice bearing the C26GM colon carcinoma and RMA T lymphoma, respectively, and to investigate whether N(G) nitro-L-arginine methyl ester (L-NAME) and sildenafil, both modulators of the arginine metabolism, restored antitumor immunity.

Results: We report here that MDSC accumulate in the spleen and blood of mice irrespective of the mouse and tumor model used. Treatment of tumor-bearing mice with either the phosphodiesterase-5 inhibitor sildenafil or the nitric-oxide synthase (NOS) inhibitor L-NAME significantly restrained tumor growth and expanded the tumor-specific immune response.
\end{abstract}

Conclusion: Our data emphasize the role of MDSC in modulating the endogenous tumor-specific immune response and underline the anti-neoplastic therapeutic potential of arginine metabolism modulators.

\section{Background}

An established tumor adopts several strategies to escape immunosurveillance and this complex phenomenon results in generation of a site of acquired immune privilege [1]. Over time, local suppression spreads systemically, thereby weakening immunological barriers that might protect against tumor metastasis. Tumor-specific suppression might explain why even immunotherapies that succeed in inducing systemic immune response are rarely of clinical effect on tumors.
As reviewed in [2], impairment in tumor antigen expression or its processing and presentation by both tumor cells and antigen presenting cells (APC), release of immunouppressive cytokines and prostaglandins as well as proapoptotic mechanisms may directly and/or indirectly impair $\mathrm{T}$ cell function while favoring tumor cell growth. Finally, tumor cells may promote development and recruitment of regulatory $\mathrm{T}$ cells (Treg) and myeloid derived suppressor cells (MDSC). CD4+CD25+Treg in particular, represent an essential mechanism of peripheral 
tolerance to self antigens [3]. They selectively express Foxp3, a forkhead/winged helix transcription factor that controls master genes in Treg development/function [3]. Several neoplasms associate with $\mathrm{CD} 4{ }^{+} \mathrm{CD} 25^{+}$Treg accumulation in the blood and/or in tumors, and this may inversely correlate with patients' survival [4].

MDSC are a heterogeneous population of cells of myeloid origin [5], and include immature macrophages, granulocytes, dendritic cells (DC) and other myeloid cells [2,5-7]. Whereas in the spleen of normal mice they account for less than $5 \%$ of the nucleated cells, they rapidly accumulate in secondary lymphoid organs, blood and tissues during inflammation and cancer $[6,8]$. Several soluble factors contribute to alteration of the normal myelopoiesis and recruitment of MDSC to peripheral organs under pathologic conditions, including IL-3, IL-6, IL-10, vascular endothelial growth factor (VEGF), macrophage colonystimulating factor (M-CSF) and granulocyte-macrophage colony-stimulating factor (GM-CSF) [6-8]. In mice, MDSC are characteristically CD $11 \mathrm{~b}^{+} \mathrm{Gr}-1^{+}$, and may also express CD31 [9], CD124, IL-4 receptor $\alpha$-chain [10] and CD80 [11]. Expression of CD115 on MDSC may correlate with their ability to mediate development of Treg [12]. In humans MDSC have been described to accumulate in the peripheral blood of patients affected by breast, lung, renal and head and neck carcinomas [6] and in melanoma [13], but their phenotype is still poorly defined. MDSC impair $\mathrm{T}$ lymphocyte functions through different mechanisms, including immunosuppressive cytokines and perturbation of the arginine metabolism by inducible nitric oxide synthase (iNOS), arginase (Arg), and reactive oxygen species [14]. More in details, iNOS produces nitric oxide (NO), which interferes with IL-2 receptor signaling [15], leading to cell cycle arrest. NO is also a key signaling molecule in inflammation-driven diseases, including cancer, where it participates to cancerogenesis, angiogenesis, tumor cell proliferation and invasion [16]. Furthermore, high Arg activity depletes arginine from the microenvironment, inhibiting T cell activation and proliferation [17], and favoring $\mathrm{T}$ cell apoptosis [14].

Several Arg and NOS inhibitors have been tested with the purpose to inhibit tumor development and favor antitumor immunity [18]. As an example, $\mathrm{N}(\mathrm{G})$-monomethyl$\mathrm{L}$-arginine as been shown to restore anti-tumor immunity in vitro [19]. Unfortunately, its use in clinic has been discontinued due to severe toxicity [18]. N(G) nitro-Larginine methyl ester (L-NAME) has been reported in several mouse models to inhibit tumor growth [20-22]. Those studies however, did not investigate a direct correlation of its effects on the endogenous tumor-specific immune response. More recently, Serafini et al. [23] reported that phosphodiesterase- 5 inhibitors (sildenafil, tadalafil and vardenafil) down regulate Arg and iNOS expression, thereby impairing the immunosuppressive activity of MDSC. In the mouse models tested, restoration of $\mathrm{T}$ cell immunity correlate with substantial delay in tumor progression [23].

We evaluated whether accumulation of MDSC occurred in $\mathrm{BALB} / \mathrm{C}$ and $\mathrm{C} 57 \mathrm{BL} / 6$ mice bearing the C26GM colon carcinoma and RMA T lymphoma, respectively, and we investigated whether L-NAME and sildenafil restored antitumor immunity and delayed tumor growth.

\section{Results and Discussion \\ MDSC accumulate in the spleen and blood of tumor- bearing mice}

We initially investigated the effect of tumor growth on myelopoiesis and recruitment of MDSC to peripheral organs in the well-characterized colon adenocarinoma C26GM model [24]. This is a more aggressive variant of the carcinogen-induced undifferentiated colon carcinoma CT26 [25], genetically modified to secrete GM-CSF [24]. C26GM is particularly interesting owing to its aggressiveness (animals are killed by the tumor in less than 2 weeks) and because of the secretion of GM-CSF, one of the factors known to alter myleopoiesis during tumor growth [7]. Hence, C26GM cells were injected s.c. in BALB/c mice, and animals were killed 9 days later, when the tumor mass had reached the dimension of approximately $600 \mathrm{~mm}^{3}$. Flow cytometry analysis of the spleen and blood of tumorbearing mice showed a dramatic accumulation of $\mathrm{CD} 11 \mathrm{~b}+\mathrm{Gr} 1+$ cells in tumor-bearing mice (Fig. $1 \mathrm{E}$ and $1 \mathrm{~F}$, respectively) when compared with naïve age- and sexmatched littermates (Fig. 1A and 1B). Quantification of $\mathrm{CD} 11 \mathrm{~b}^{+} \mathrm{Gr} 1^{+}$cells demonstrated a statistically significant increase in both the spleen and blood of tumor-bearing mice (Fig. 1I and 1J). Interestingly, a second population of

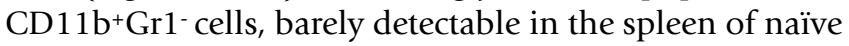
$\mathrm{BALB} / \mathrm{c}$ mice, became well represented in tumor-bearing mice, therefore confirming previous reports [24]. $\mathrm{CD} 11 \mathrm{~b}^{+} \mathrm{Gr} 1^{-}$cells were already detectable in the blood of naïve $\mathrm{BALB} / \mathrm{c}$ mice, and marginally increased during tumor growth (Fig. 1B, F and 1J). It has been reported that both populations suppress $\mathrm{CD} 8^{+} \mathrm{T}$ lymphocytes [10], suggesting that $\mathrm{Gr} 1^{+}$and $\mathrm{Gr} 1^{-}$fractions of $\mathrm{CD} 11 \mathrm{~b}^{+}$cells are differentiation steps of the same MDSC population. Indeed, $\mathrm{CD} 11 \mathrm{~b}^{+} \mathrm{Gr} 1{ }^{+}$cells may differentiate both in vitro and in vivo into Gr1- cells [26-28].

To verify whether the $\mathrm{CD} 11 \mathrm{~b}^{+}$cells accumulating in tumor-bearing BALB/c mice were "bona fide" MDSC, splenic CD $11 b^{+}$cells were purified by magnetic bead sorting, and tested for their immunosuppressive activity in standard in vitro proliferation assays. Indeed, CD11 b cells purified from C26GM tumor-bearing mice were able to substantially abrogate the proliferation of BALB/c splenocytes stimulated with either anti-CD3 and anti-CD28 anti- 


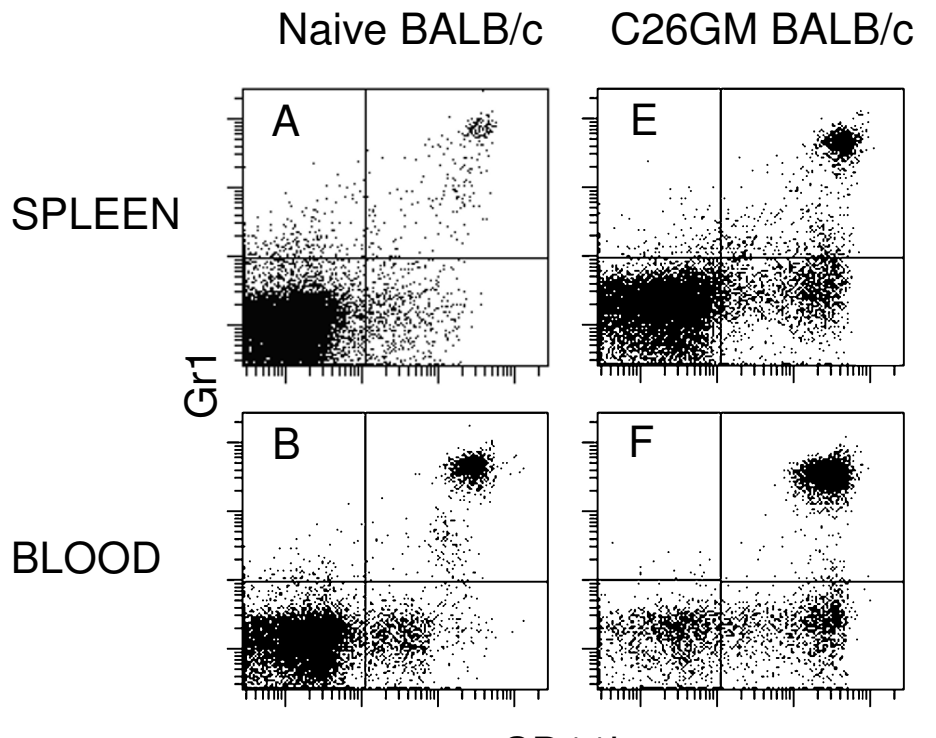

CD11b

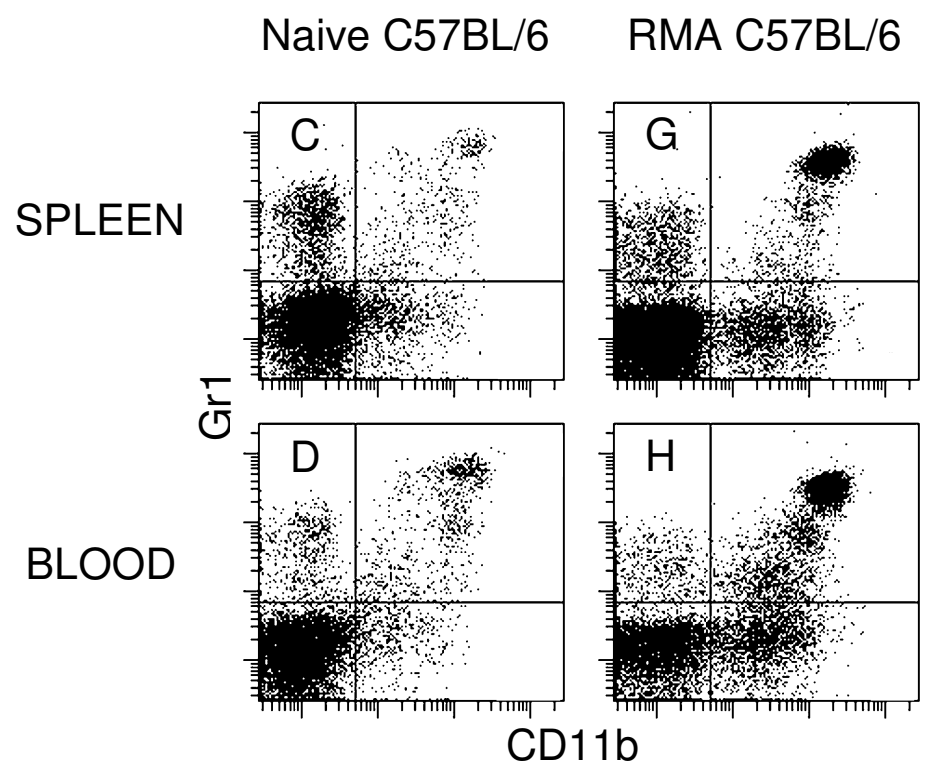

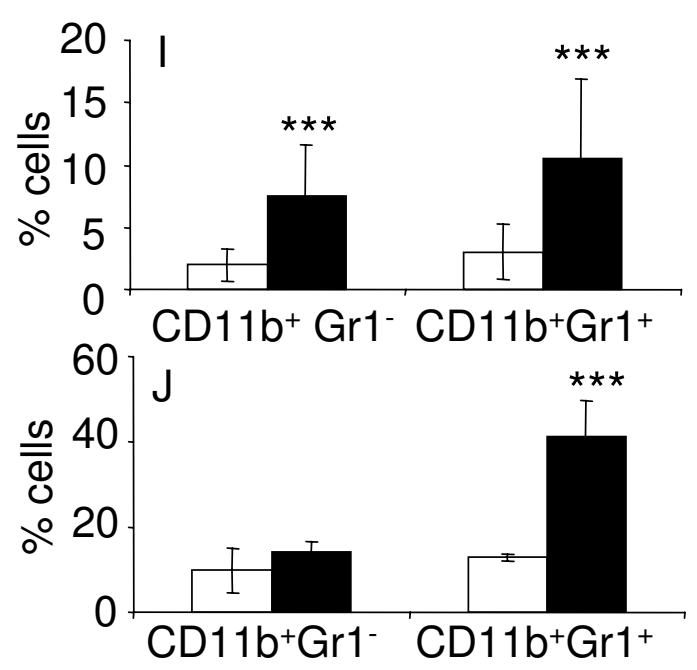

$\square$ Naive mice

Mice with tumor
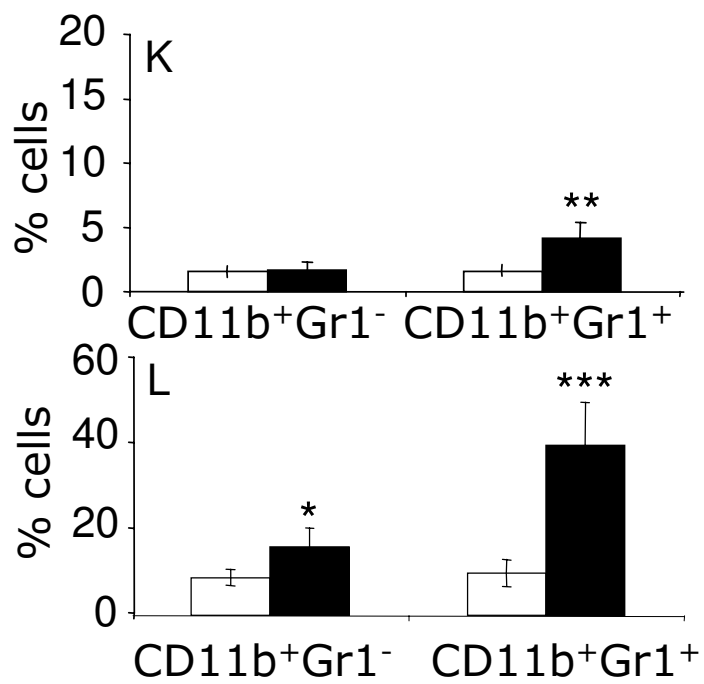

Figure I

Tumor-bearing mice have an expanded pool of MDSC in spleen and blood. Splenocytes and blood cells from naïve $(A-D)$ and tumor bearing BALB/c (E, F) and C57BL/6 mice $(G, H)$ were stained for CDI Ib and Gr I markers and analyzed by flow cytometry as detailed in the Materials and Methods section. Dot plot panels are representative of 8 independent experiments for a total 10 naïve $(A, B)$ and 38 tumor-bearing $B A L B / c$ mice $(E, F)$ and 15 naive $(C, D)$ and 15 RMA-bearing C57BL/6 mice $(\mathrm{G}, \mathrm{H})$, respectively. Histograms report the percentage of $\mathrm{CDI} \mathrm{Ib} \mathrm{Grl}^{-}$and $\mathrm{CDIIb}^{+} \mathrm{Grl}^{+}$cells as aggregated data (average \pm SD) for the BALB/c (I, J) and the C57BL/6 models (K, L), respectively. Statistic analysis of collected data was performed using the Student's T test; ${ }^{* * *} \mathrm{p}<0.00 \mathrm{I},{ }^{* *} 0.00 \mathrm{I}<\mathrm{p}<0.05$. 
bodies (Fig. 2A) or $\gamma$-irradiated C57BL/6 splenocytes (Fig 2B).

The immune response to pathogens and tumors is genetically controlled, and may diverge in different mouse strains. As an example, BALB/c mice are considered a Th2 prone strain, whereas Th1 responses dominate in C57BL/ 6 mice. Because Th2-associated cytokines (e.g. IL-6) and other soluble factors are needed to alter normal myelopoiesis and favor recruitment of MDSC to peripheral organs [6-8], and both Th1 (IFN- $\gamma$ ) and Th2 (IL-13) cytokines are required for activation of MDSC [10], a balance between Th1 and Th2 immune responses may be required for MDSC accumulation and immunosuppressive function during tumor progression. To investigate whether similar populations of MDSC accumulated also in a Th1-prone strain upon tumor challenge, $\mathrm{C} 57 \mathrm{BL} / 6$ mice were implanted s.c. with RMA cells, a Rauscher virus-induced T lymphoma [29]. Because RMA is less aggressive than C26GM, mice were killed 2 weeks after tumor challenge, time at which the mass had reached a dimension of approximately $400 \mathrm{~mm}^{3}$. Tumor-associated accumulation of $\mathrm{CD} 11 \mathrm{~b}^{+} \mathrm{Gr} 1^{+}$cells in the blood of $\mathrm{C} 57 \mathrm{BL} / 6$ mice was comparable to the one found in tumor-bearing BALB/c mice (Fig. 1D, $\mathrm{H}$ and $1 \mathrm{~L}$ and $1 \mathrm{~B}, \mathrm{~F}$ and $1 \mathrm{~J}$, respectively). A less dramatic but still statistical significant accumulation of $\mathrm{CD} 11 \mathrm{~b}^{+} \mathrm{Gr} 1^{+}$cells was evident also in the spleen of mice bearing RMA lymphomas (Fig. 1C, G and 1K). Accumulation of $\mathrm{CD} 11 \mathrm{~b}^{+} \mathrm{Gr} 1^{-}$cells was less conspicuous in C57BL/6 mice than in tumor-bearing BALB/c mice (Fig.
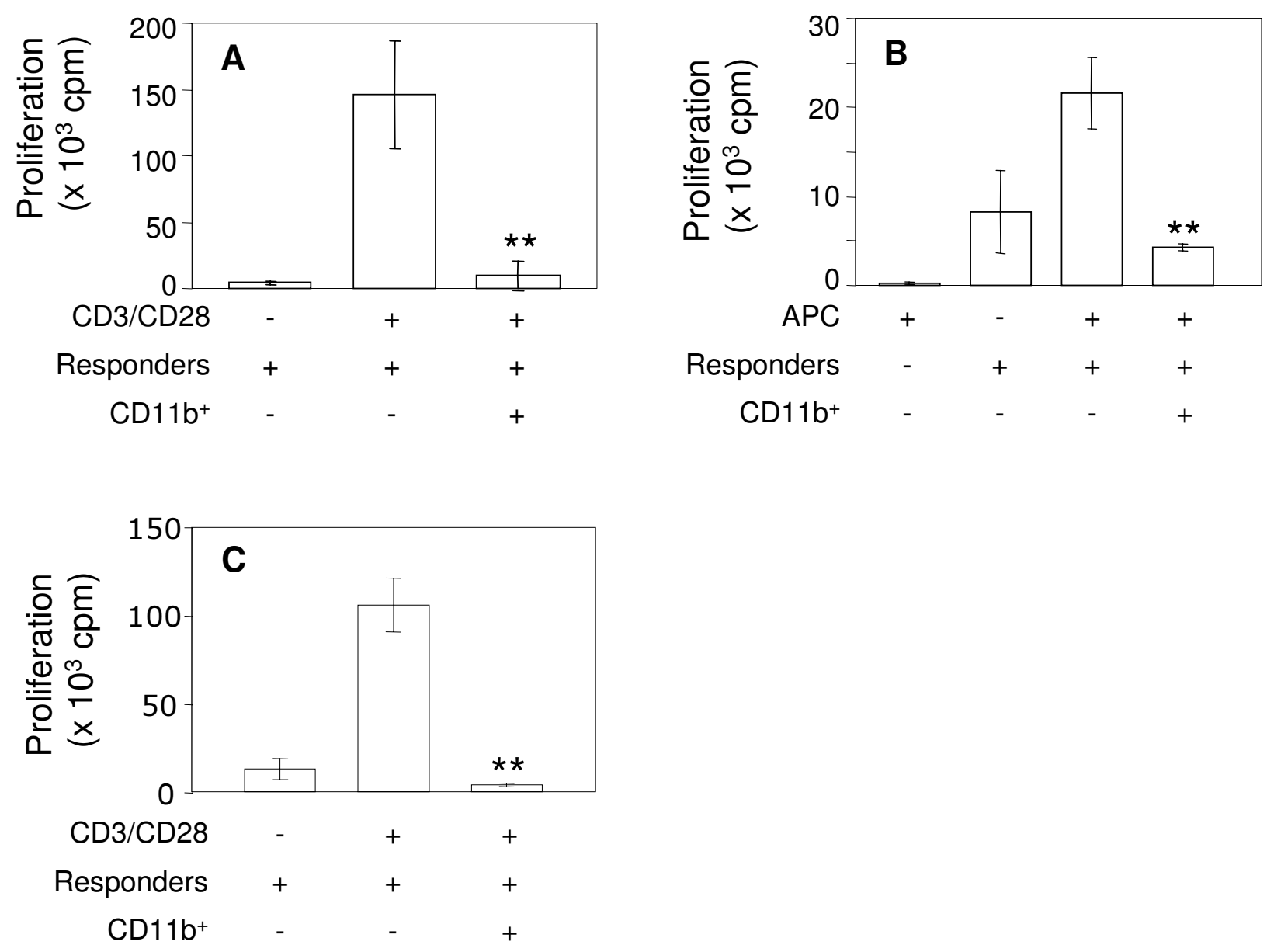

\section{Figure 2}

MDSC suppress $T$ cells proliferation. MDSC were purified as CDII l b cells from the spleen of C26GM (A, B) and RMA (C) tumor bearing mice by immunomagnetic beads sorting as detailed in the Materials and Methods section. $\mathrm{CDI}$ I $\mathrm{b}^{+}$cells were added at a final concentration of $20 \%$ to a mixed leukocyte culture set up with splenocytes, as responders, stimulated with antiCD3 and anti-CD28 antibodies (A, C) or with an equal number of $\gamma$-irradiated C57BL/6 splenocytes (B). Data are representative of at least two experiments and are expressed as the cpm mean \pm SD of triplicates. Student's T test: $* * 0.00 I<p<0.05$. 
$1 \mathrm{~K}$ and $1 \mathrm{~L}$ and $1 \mathrm{I}$ and $1 \mathrm{~J}$, respectively), and was statistically significant only when blood samples from naïve and tumor-bearing mice were compared (Fig. 1L). Nevertheless, CD $11 b^{+}$cells purified from RMA tumor-bearing mice inhibited proliferation of syngenic splenocytes to an extent comparable to CD $11 b^{+}$cells purified from C26GM tumor-bearing mice (Fig. 2C).

Hence, tumor-induced altered regulation of myelopoiesis and accumulation of MDSC is a characteristic common to Th1 and Th2 strains as well as to tumors of different aggressiveness. Quantitative and qualitative differences in MDSC populations found in the two models may depend on several factors, among which the genetic background, tumor aggressiveness, and soluble factors released by tumor and stroma cells, including bone marrow derived cells, fibroblasts and endothelial cells [30].

Treatment of tumor-bearing mice with Arg and iNOS inhibitors restrain tumor growth

Accumulation of MDSC in both BALB/c- and RMA-bearing mice suggested that alteration of arginine metabolism
[31] was a relevant mechanism of immunoescape in these models, and that drugs able to modulate arginine metabolism [18] were potentially useful in crippling the immunosuppressive activity of MDSC and delaying tumor growth. To verify this hypothesis, BALB/c mice were challenged s.c. with C26GM cells, and L-NAME or sildenafil were administered starting on the day of tumor challenge. To identify the best delivery strategy, drugs were administered either i.p. or in the drinking water. As control, animals were treated with vehicle (i.e., PBS) only. Both inhibitors significantly delayed tumor growth by approximately 50\% when compared with vehicle-treated mice, and both regimens were equally effective (Fig. 3A).

Similar experiments were conducted in the RMA model. Having verified in the C26GM model that the two delivery strategies were equally effective, and to avoid distress and/ or pain to the animals, drugs were administered in the drinking water. Also in this model, L-NAME delayed tumor growth by approximately 50\% (Fig. 3B). Conversely, sildenafil did not appear to be effective against RMA lymphoma. The scarce efficacy of sildenafil in

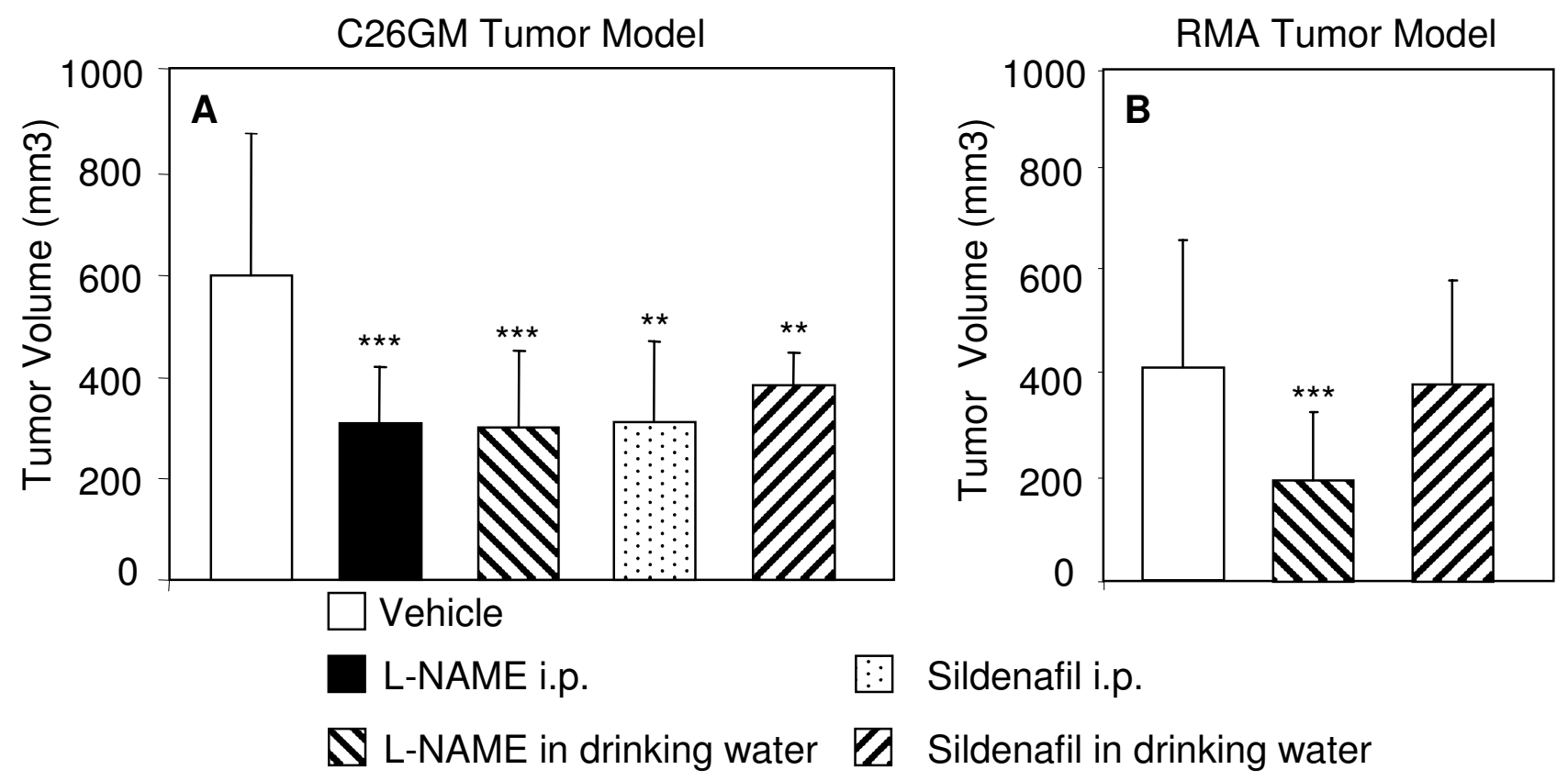

Figure 3

Modulators of arginine metabolism restrain tumor growth. BALB/c (A) and C57BL/6 mice (B) were challenged s.c. with C26GM and RMA cells, respectively. The same day mice were randomly assigned to either one of the following treatments: L-NAME or sildenafil (given i.p. or dissolved in drinking water) or vehicle (PBS) i.p. (see Materials and Methods section for experimental details). Tumor volume (expressed as $\mathrm{mm}^{3}$ ) was measured by caliper at day 9 and I5, respectively. Panels report the cumulated data of at least three independent experiments performed with the following number of animals: C26GM model: Vehicle: $n=24$, L-NAME i.p.: $n=15$, L-NAME o.s.: $n=14$, Sildenafil i.p.: $n=10$, Sildenafil o.s.: $n=5$; RMA model: Vehicle: $\mathrm{n}=$ I5, L-NAME o.s.: $\mathrm{n}=15$, Sildenafil o.s.: $\mathrm{n}=10$. Student's T test: ${ }^{* * *} \mathrm{p}<0.001, * * 0.001<\mathrm{p}<0.05$. 
restraining RMA growth does not appear to be related to the mouse strain, because Serafini et al. reported an excellent effect of sildenafil in C57BL/6 mice challenged with the fibrosarcoma MCA203 [23]. This discrepancy may more likely be related to the characteristics of the two tumor models (e.g., cytokine production, immunogenicity, aggressiveness, stromal reaction).

Since chronic treatment with NO inhibitors has been reported to be associated with systemic toxicity [32], we monitored animal weight, as a measure of potential drugrelated toxicity, and we found no difference between drug and vehicle-treated mice in both strains (Fig. 4A and 4B). The respiratory apparatus (i.e., bronchial tree and lung), esophagus, kidney, suprarenal gland and liver of L-NAME treated animals were also macroscopically and microscopically investigated by an expert pathologist and found with no sign of drug-related toxicity (data not shown). Absence of drug-related toxicity in our animal models might be related to the relatively short period of treatment. Indeed, glomerulosclerosis, one of the effects of LNAME, is usually found in animals treated for a longer period of time [33].

\section{Modification of tumor-associated myelopoiesis induced by modulators of arginine metabolism}

We investigated whether treatment with L-NAME or sildenafil modified accrual of MDSC in the spleen and blood of tumor-challenged mice. Flow cytometry analyses conducted ex vivo the day of mouse killing showed a clear accumulation of both $\mathrm{CD} 11 \mathrm{~b}+\mathrm{Gr} 1{ }^{+}$and $\mathrm{CD} 11 \mathrm{~b}^{+} \mathrm{Gr} 11^{-}$cells in the spleen of BALB/C mice bearing C26GM tumors, but neither L-NAME nor sildenafil altered such recruitment (Fig 5A). Conversely, CD $11 \mathrm{~b}^{+} \mathrm{Gr} 1^{+}$cells dropped by $50 \%$ in the blood of tumor-bearing mice treated with either LNAME or sildenafil, when compared with samples collected from untreated tumor-bearing mice (Fig. 5B). This was not confirmed in the RMA model, despite a comparable recruitment of $\mathrm{CD} 11 \mathrm{~b}^{+} \mathrm{Gr} 1^{+}$cells (Fig. 5D). Hence, LNAME, although highly effective in restraining tumor growth in both models, do not appear to consistently perturb the tumor-associated recruitment of $\mathrm{CD} 11 \mathrm{~b}^{+} \mathrm{Gr} 1^{+}$ cells. To gain further insight on the mechanism underlying the therapeutic effect of L-NAME, we assessed the enzymatic activity of MDSC cells purified from the spleen of RMA-bearing mice. Magnetic bead-purified CD11 $\mathrm{b}^{+}$ cells from L-NAME treated animals showed a relevant reduction in Arg activity when compared with those obtained from control animals treated with vehicle (Fig.
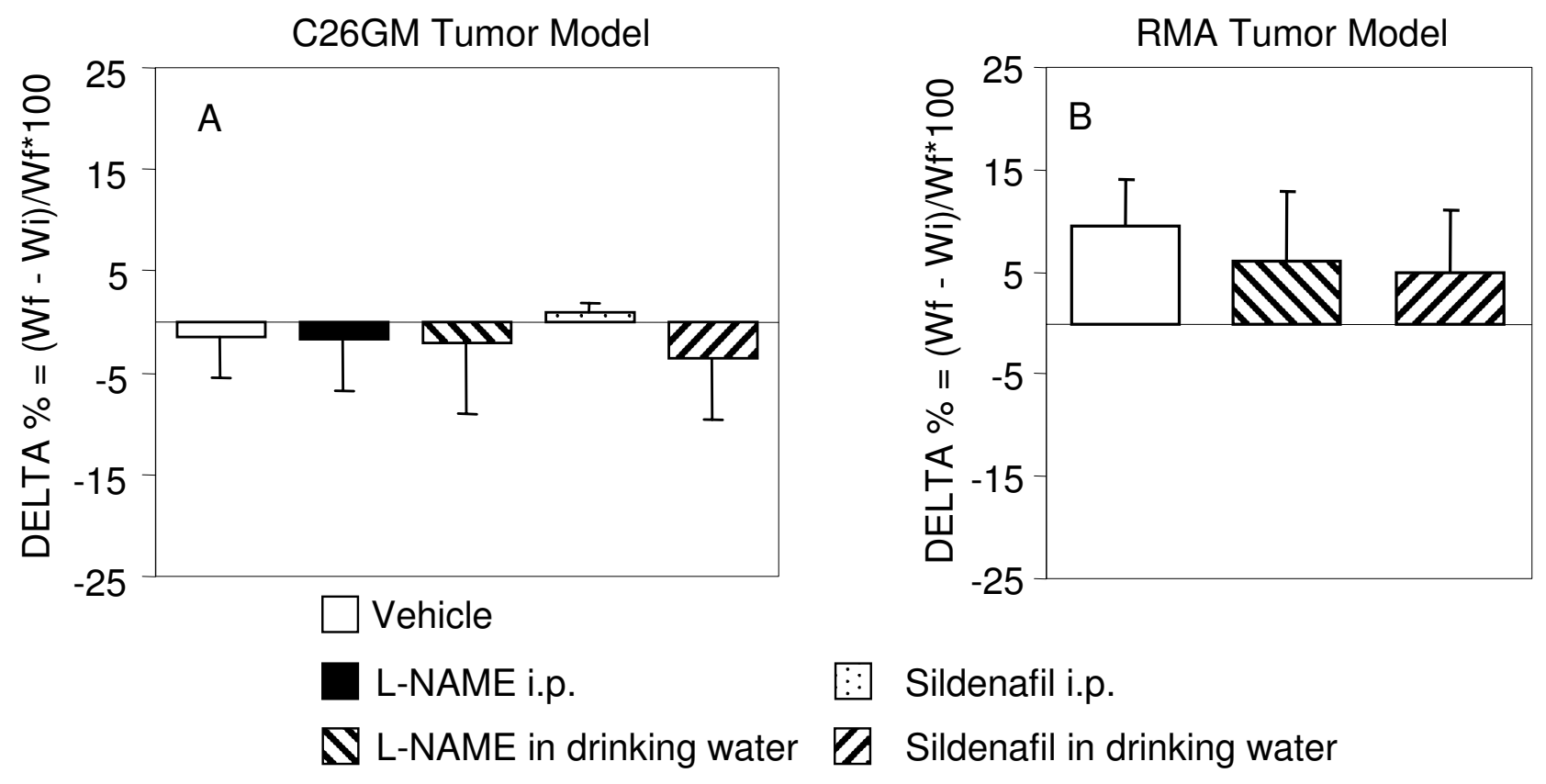

Figure 4

Modulators of arginine metabolism do not cause loss of body weight in treated animals. Toxicity of L-NAME and sildenafil was evaluated as loss of body weight, defined as Delta $\%=($ final weight - initial weight)/initial weight $\times 100$. BALB/c mice challenged with C26GM cells (A) and C57BL/6 mice challenged with RMA cells (B) were weighed at day 0 and at day 9 and I5, respectively. The experimental groups are described in the legend to Fig. 3. 
C26GM Spleen

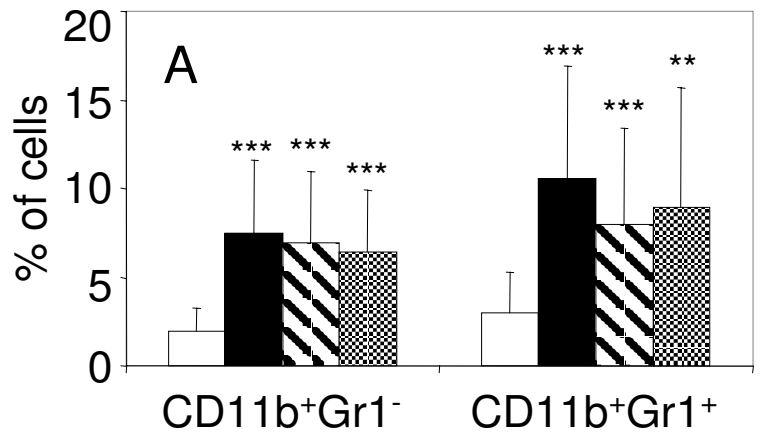

C26GM Blood

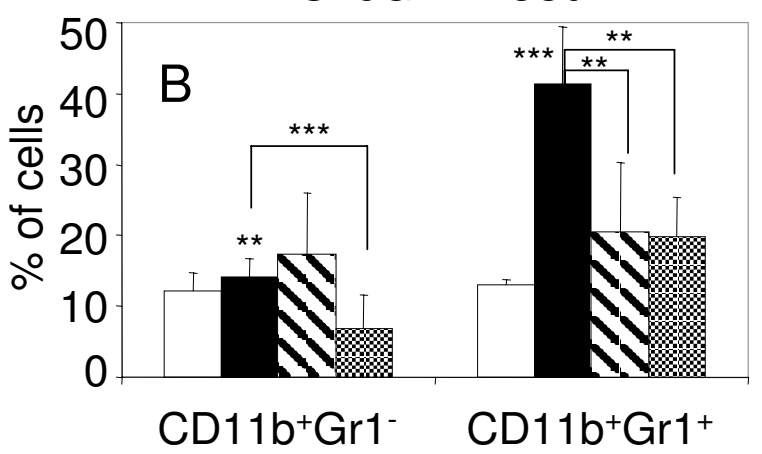

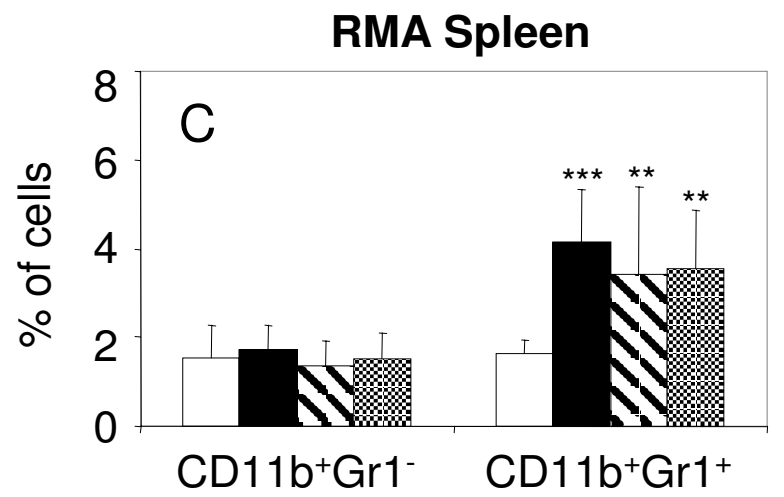

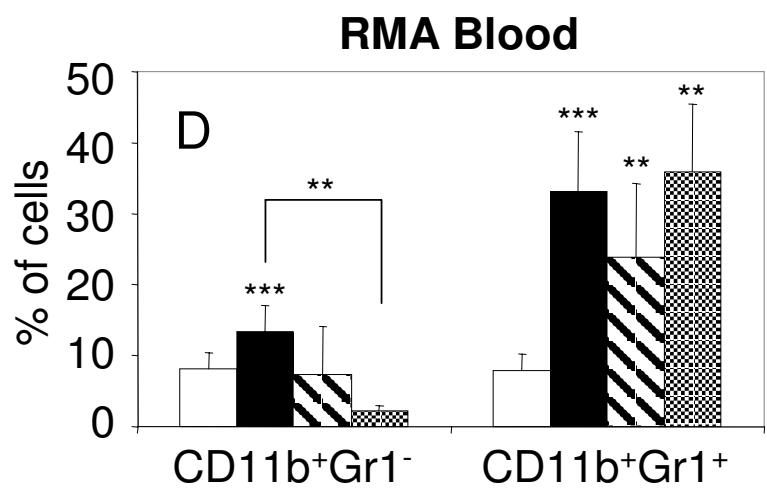

$\square$ No tumor

$\boldsymbol{\nabla}$ With tumor, L-NAME

With tumor, Sildenafil

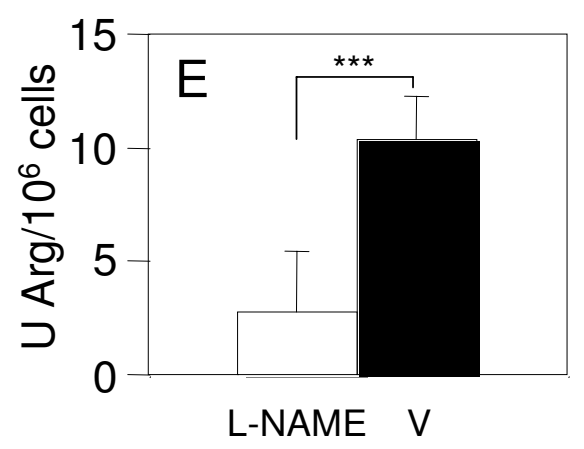

Figure 5

Modulators of arginine metabolism alter MDSC accumulation in the blood of tumor-bearing mice. BALB/C and C57BL/6 mice were challenged s.c. with C26GM and RMA cells, respectively. The same day, mice were randomly assigned to either one of the following treatments: L-NAME or sildenafil (given i.p. or dissolved in drinking water) or vehicle (PBS; V) i.p. (see Materials and Methods section for experimental details). Tumor-bearing BALB/C and C57BL/6 mice were killed 9 and I5 day later. Recruitment of $C D \mid l b^{+} \mathrm{Grl}-$ and $C D I I b+G r l^{+}$cells in the spleen $(A, C)$ and blood (B, D) of tumor-bearing BALB/c $(A, B)$ and $C 57 B L / 6$ mice (C, D) was investigated by flow cytometry. Histograms report the percentage of $C D I I b^{+} G r l^{-}$and $\mathrm{CDI} \mathrm{lb}^{+} \mathrm{Grl}^{+}$cells as aggregated data (average $\pm \mathrm{SD}$ ) for the experimental groups reported in the legend of Fig. 3. Alternatively, magnetic bead sorted CDI Ib+ cells from the spleen of RMA (E) tumor bearing mice were lysed and analyzed for relative Arg enzyme activity. Student's T test: $*^{* *} p<0.001$, $* * 0.00 \mathrm{I}<\mathrm{p}<0.05$. 
$5 \mathrm{E})$, therefore confirming that in vivo L-NAME is a potent inhibitor of Arg [34].

In both tumor models a reduction statistically significant of CD11 b+Gr1- cells was evident in the blood of sildenafiltreated mice when compared with untreated ones (Fig. 5B and 5D). Hence, it might be possible that sildenafil acts primarily on terminally differentiated $\mathrm{CD} 11 \mathrm{~b}^{+} \mathrm{Gr} 1^{-}$cells [27]. Together with the notion that in vivo sildenafil treatment reduces the enzymatic activity of iNOS and Arg in MDSC [23], our findings support the hypothesis that sildenafil has a potent inhibitory impact on the MDSCmediated immunosuppressive mechanisms. Because sildenafil caused delayed tumor growth and a significant fall of both MDSC populations only in the C26GM model, it might be possible that sildenafil-induced containment of tumor growth is obtained only when myelopoiesis is redirected to more physiologic conditions. These hypotheses need further experimental support.

\section{Treatment with L-NAME does not perturb tumor-draining lymph node cell composition}

Lymph nodes draining a tumor mass (TDLN) or the site of vaccination rapidly enlarge owing to the accumulation of myeloid and lymphoid cells $[35,36]$. We asked whether arginine metabolism inhibitors could alter recruitment of T lymphocytes in TDLN. Because L-NAME demonstrated to be effective in restraining tumor growth in both models, we focused on this inhibitor. Hence, BALB/c mice were challenged with C26GM cells and treated with LNAME or vehicle as described above. A 3-fold increase in cell number was evident in TDLN when compared with LN from naïve mice, and was not modified by L-NAME treatment (Fig. 6A). Flow cytometry analysis of TDLN cells showed a considerable increase in the number of both CD4 and CD8 cells (Fig. 6D and 6H, respectively). Curiously enough, the percentage of CD8 and more evidently of CD4 ${ }^{+} \mathrm{T}$ cells in TDLN decreased in both L-NAME and vehicle-treated mice (Fig. 6G and 6C, respectively), suggesting that in TDLN a relevant perturbation of the physiologic equilibrium among the different cell populations was undergoing, that was not modified by L-NAME.

We recently reported that Treg accumulate in TDLN as well as in LN draining the site of vaccination [36], therefore suggesting that such recruitment is a physiologic hallmark of sites were an active immune response is taking place. Because MDSC can favor induction of Treg [12], we also investigated whether Treg recruitment in TDLN of $\mathrm{BALB} / \mathrm{c}$ mice bearing C26GM tumors was further increased by tumor-associated MDSC and modified by LNAME treatment. The absolute number of CD $4{ }^{+} \mathrm{CD} 25^{+}{ }^{+}$oxp $3+$ cells dramatically increased in TDLN, but was not modified by L-NAME treatment (Fig. 6L).
When similar analyses were conducted in TDLN collected from RMA-bearing C57BL/ 6 animals, results substantially overlapped the ones obtained in BALB/C mice bearing C26GM tumors. Indeed, no substantial differences in percentage and absolute number of CD4 and CD8 T cells were found in L-NAME and vehicle-treated mice (Fig. 6F and $6 \mathrm{~J}$, respectively). A slightly and yet statistically significant reduction in the absolute number of Treg was found in TDLN from L-NAME treated animals (Fig. 6N). A similar result was obtained in sildenafil treated animals (absolute number of Treg: 10,00 $\pm 0,24 \times 10^{3} ; \mathrm{n}=5$ ).

All together, these data suggest that L-NAME does not substantially modify the physiologic perturbation of LN composition in TDLN.

\section{Treatment with L-NAME augments the endogenous antitumor immunity}

Our final goal was to investigate the effects of L-NAME on the endogenous tumor-specific immune response. RMA is an immunogenic tumor (i.e. upon in vivo growth it spontaneously induces an endogenous tumor-specific immune response [37]), whose immunogenicity is strongly biased by the expression of dominant viral antigens [38]. Hence, splenocytes recovered from L-NAME and vehicle-treated C57BL/6 mice bearing RMA tumors, were specifically restimulated in vitro and tested for their ability to recognize different targets. Flow cytometry analyses showed that cultures from L-NAME-treated mice contained a frequency of $\mathrm{CD}^{+} \mathrm{T}$ cells producing IFN- $\gamma$ upon RMA challenge (Fig. $7 \mathrm{E})$ higher than the one found in cultures from vehicletreated mice (Fig. 7C). IFN- $\gamma$ release was specific because the percentage of cells challenged with the irrelevant target EL4G- was at background level in both cultures (Fig. $7 \mathrm{~F}$ and $7 \mathrm{D}$ ). RMA-specific response was not due to a in vitro priming, because cells from naïve animals did not produce IFN- $\gamma$ above background level when challenged with the targets (Fig. 7A and 7B).

Since it is well known that NO participates in the regulation of various cell activities, to exclude that L-NAME and sildenafil exerted a direct effect on RMA cells by affecting doubling time and/or favoring apoptosis, we assessed the in vitro proliferation potential of RMA cells in the presence of either one of two drugs. Both L-NAME and sildenafil neither altered RMA proliferation rate, nor increased apoptosis (data not shown), therefore excluding this possibility.

Taken together, these data demonstrate that L-NAME treatment has the potential to augment the endogenous antitumor immunity. Because MDSC seem not to block the early events of T cell activation and IFN- $\gamma$ production [10], we can hypothesize that L-NAME favors IFN- $\gamma$ production by other yet uncovered mechanisms. 
C26GM Tumor Model
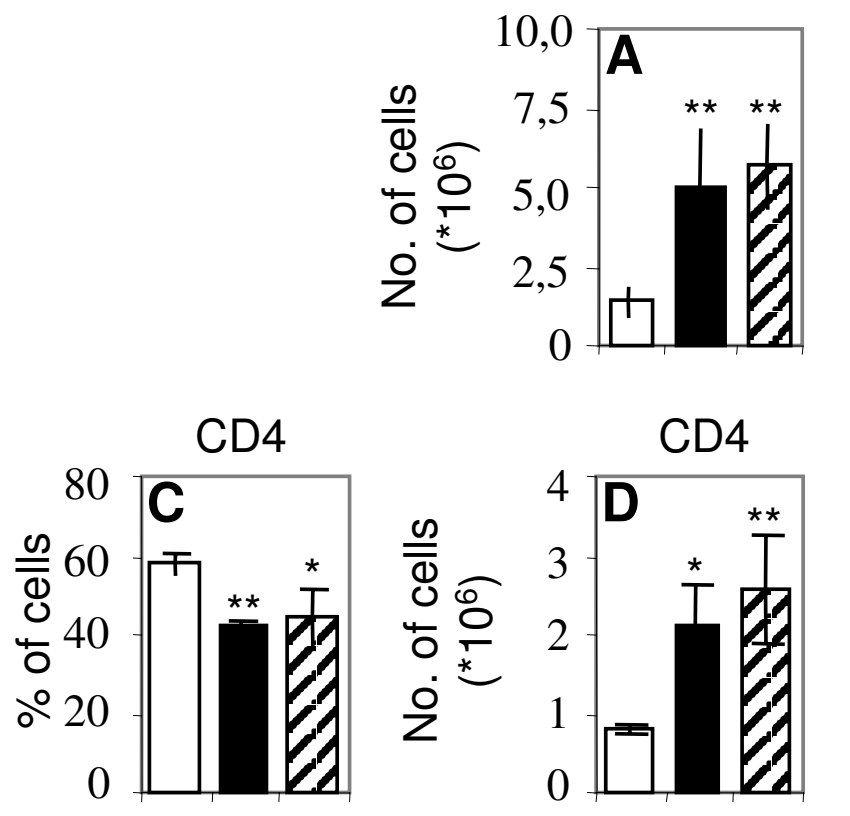

$\square$ Naive

- Tumor, V

C. Tumor, L-NAME

RMA Tumor Model

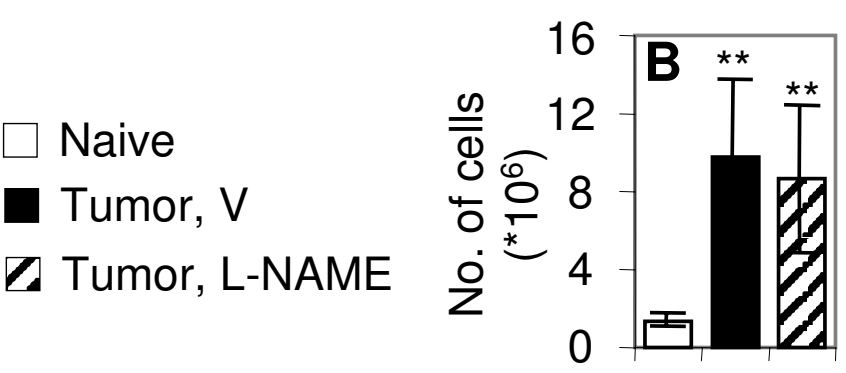

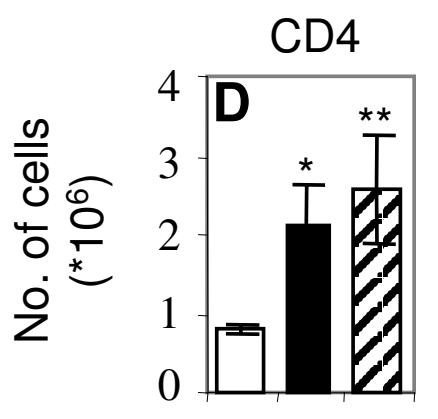
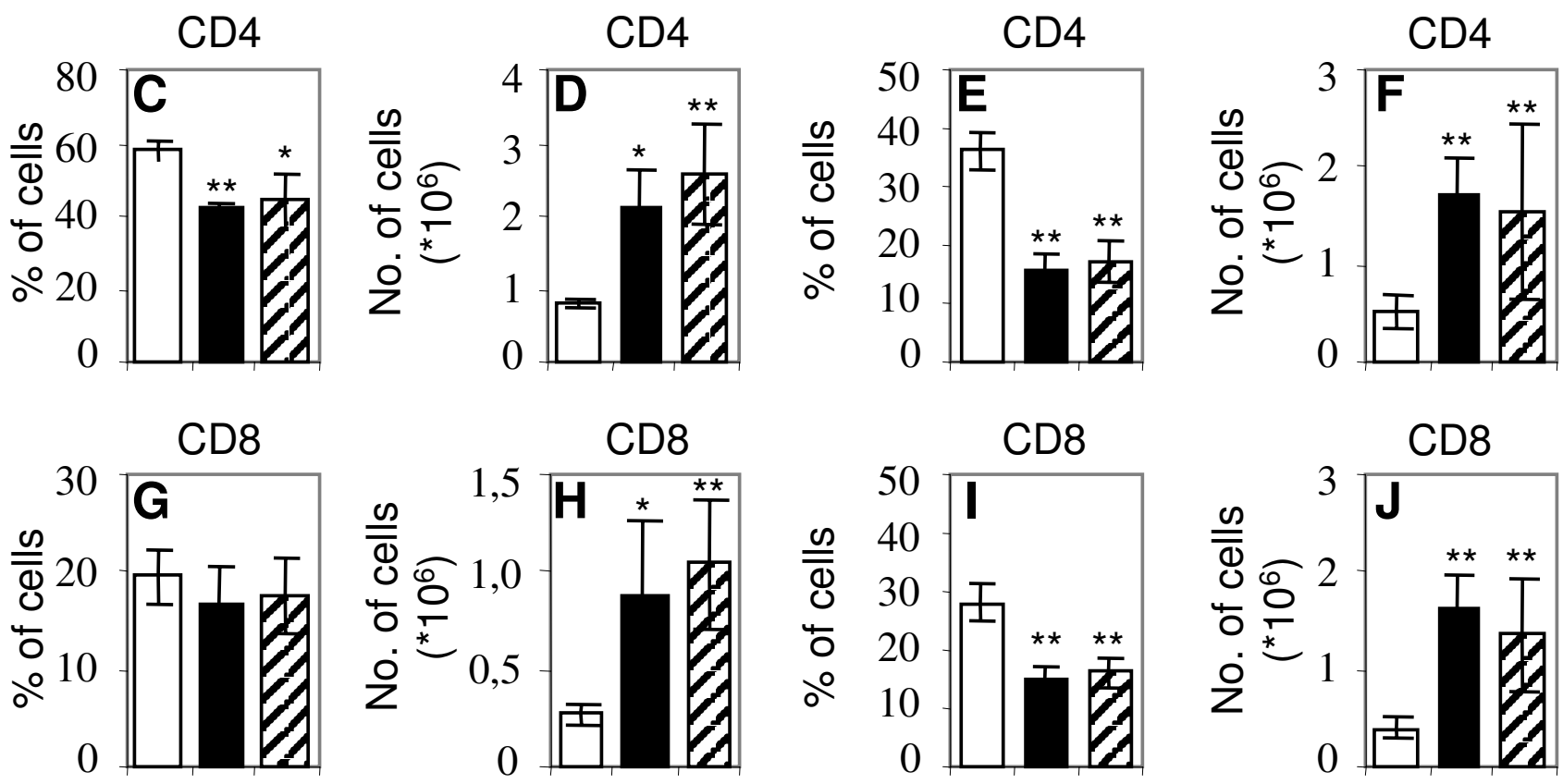
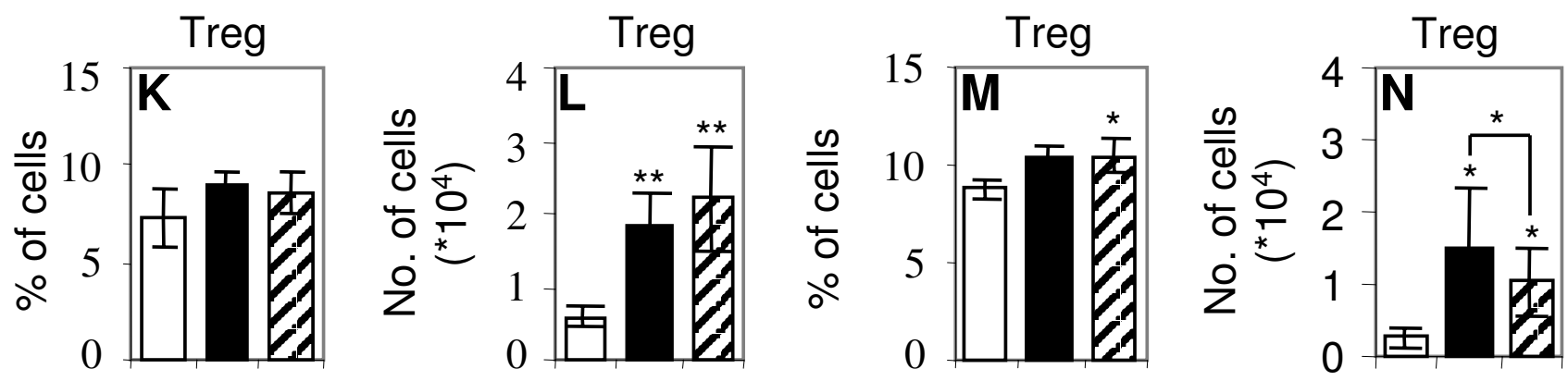

Figure 6

Treatment of tumor-bearing mice with L-NAME does not perturb TDLN cell composition. Cells from TDLN of C26GM- and RMA-bearing mice treated with L-NAME or vehicle $(V)$ and from LN of naïve strain-related mice were either enumerated $(A, B)$ or stained with $T$ cell markers and analyzed by flow cytometry. Histograms report the percentage and absolute number of $\mathrm{CD}^{+}(\mathrm{C}, \mathrm{E}$, and $\mathrm{D}, \mathrm{F}), \mathrm{CD}^{+}(\mathrm{G}, \mathrm{I}$, and $\mathrm{H}, \mathrm{J})$, and $\mathrm{CD} 4^{+} \mathrm{CD} 25^{+}$Foxp3 $3^{+} \mathrm{T}$ cells (Terg; K, M, and L, N), respectively, as aggregated data (average \pm SD) for the experimental groups reported in the legend of Fig. 3. Student's T test: $* * 0.00$ I $<p<0.05, *_{p}<0.05$ 
RMA EL4G-
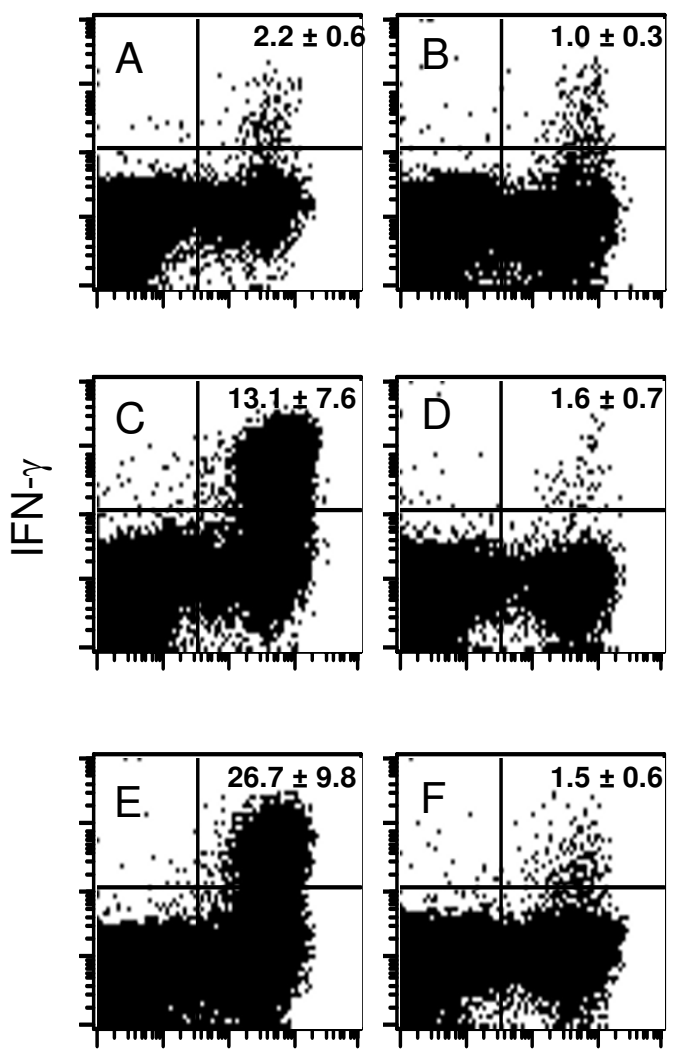

CD44
NAIVE

RMA, V

RMA, L-NAME

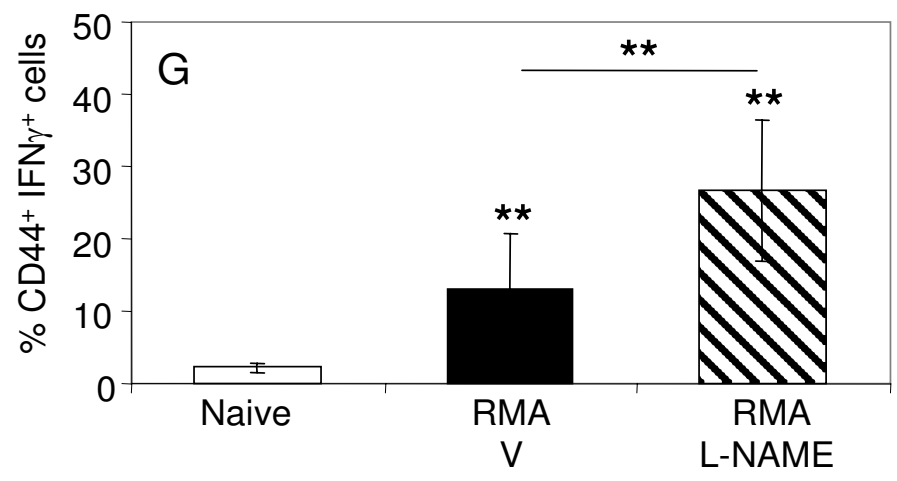

\section{Figure 7}

Treatments with L-NAME improves IFN- $\gamma$ release. C57BL/6 mice were challenged with RMA cells and treated with LNAME (E, F) or vehicle (V; panels $C$ and D). After I 5 days, animals were killed and their splenocytes were specifically restimulated in vitro. Blasts were tested for IFN- $\gamma$ production (upon challenge with RMA or EL4G-) and analyzed by FACScalibur ${ }^{\circledR}$ after co-staining with $\mathrm{mAb}$ against CD8, CD44 and IFN- $\gamma$. Panel A and B report representative dot plot analyses of blasts from cultures of naïve splenocytes that were challenged with RMA (A) or EL4G- targets (B). The percentage of CD8 $8^{+}$IFN- $\gamma^{+}$cells is reported in each panel as average $\pm S D$ of at least five animals for experimental group. The same data is reported in histogram $\mathrm{G}$ together with the statistical analysis. Student's T test: $* * 0.00 \mathrm{I}<\mathrm{p}<0.05$. 


\section{Conclusion}

Elucidation of the mechanisms by which a growing tumor eludes immunosurveillance and identification of strategies to overcome tumor-associated immunosuppression are essential issues that need to be addressed, in order to obtain the most rewarding clinical benefits from the application of immunotherapeutic strategies to cancer patients. Our results, obtained in different tumor models and murine strains, indicate that tumor growth is associated with perturbation of myelopoiesis and accumulation of MDSC. Treatment of tumor-bearing mice with modulators of arginine metabolism may modify such accrual, augment the endogenous tumor-specific immune response and restrain tumor growth.

Because neither in our nor in other tumor models inhibition of MDSC function by different means caused complete tumor regression $[21,23,39,40]$, it is likely that acting simultaneously on more than one of the know tumor-associated immunosuppressive mechanisms will result in more successful therapeutic effects. As an example, sildenafil treatment improves the efficacy of adoptive cell therapy [23]. Further investigation in this direction is warranted to confirm this hypothesis.

\section{Methods \\ Cell lines and reagents}

C26GM $\left(\mathrm{H}-2^{\mathrm{d}}\right)$ is a carcinogen-induced colon carcinoma subcloned from the CT26 cell line, and genetically modified to produce GM-CSF [24]. Cells were cultured in DMEM (Invitrogen, Milano, Italy) supplemented with 2 $\mathrm{mM}$ L-glutamine, $150 \mathrm{U} / \mathrm{ml}$ streptomycin, $200 \mathrm{U} / \mathrm{ml}$ penicillin and $10 \%$ heat-inactivated FBS (Invitrogen). RMA $\left(\mathrm{H}-2^{\mathrm{b}}\right)$ is a Rauscher virus-induced thymoma [29]. EL4G$\left(\mathrm{H}-2^{\mathrm{b}}\right)$ is a 9,10-dimethyl-1,2-benzanthracene induced thymoma [41]. Both cell lines were cultured in RPMI1640 (Invitrogen) supplemented with $2 \mathrm{mM} \mathrm{L}$-glutamine, $150 \mathrm{U} / \mathrm{ml}$ streptomycin, $200 \mathrm{U} / \mathrm{ml}$ penicillin and 10\% heat-inactivated FBS (Invitrogen). Unless specified, all chemical reagents were from Sigma-Aldrich, and monoclonal antibodies $(\mathrm{mAb})$ were from BD PharMingen (San Diego, CA).

\section{Mice and in vivo experiments}

$\mathrm{BALB} / \mathrm{C}\left(\mathrm{H}-2^{\mathrm{d}}\right)$ and $\mathrm{C} 57 \mathrm{BL} / 6\left(\mathrm{H}-2^{\mathrm{b}}\right)$ female mice, $8-10$ weeks old, were purchased from Charles River (Calco, Italy), housed in a specific pathogen-free animal facility, and treated in accordance with the European Union guidelines, and with the approval of the Institutional Ethical Committee (IACUC approval \# 311). Five hundred thousand C26GM cells and $7 \times 10^{4}$ RMA cells were injected s.c. on the left flank of BALB/c and C57BL/ 6 mice, respectively. L-NAME (given i.p. at $80 \mathrm{mg} / \mathrm{Kg} / 24 \mathrm{~h}$ or added in drinking water at $1 \mathrm{~g} / \mathrm{L}$ ) or sildenafil (Pfizer, New York, NY, given i.p. at $20 \mathrm{mg} / \mathrm{Kg} / 24 \mathrm{~h}$ or dissolved in drinking water at $20 \mathrm{mg} / \mathrm{Kg} / 24 \mathrm{~h}$ ) were administered starting on the day of tumor challenge. As control, groups of animals were treated with vehicle (PBS) only. Water was given ad libitum. Calculation of the dosage of each drug was based on the assumption that a mouse drinks approximately $3 \mathrm{ml} / 24 \mathrm{~h}$. Tumor size was evaluated by measuring two perpendicular diameters by a caliper every other day, and BALB/C and C57BL/6 mice were sacrificed after 9 and 15 days, respectively. When needed, several organs were collected, fixed in $4 \%$ formalin for $6 \mathrm{~h}$, then embedded and included in paraffin wax as previously described [42]. Five-mm thick sections were cut and stained with H\&E (Bio-Optica, Milano, Italy).

\section{Phenotypic characterization of cell populations}

TDLN and LN from naïve mice and tumor-challenged mice were processed on a cell strainer and stained with FITC-labeled anti-CD4, PE- labeled anti-CD44 and PerCPCy 5.5-labeled anti-CD8 mAb. Dead cells were excluded by physical parameters and/or by the addition of ToPro- 5 (Molecular Probes, Eugene, OR) immediately before flow cytometry analysis. For enumeration of MDSC cells, blood and splenocytes from naïve and tumor-challenged mice were stained with FITC-conjugated CD11b and APCconjugate $\mathrm{Gr} 1 \mathrm{mAb}$. For enumeration of CD $4{ }^{+} \mathrm{CD} 25^{+}{ }^{-F o x p} 3+$ cells, LN cells were stained with FITClabeled anti-CD4, PerCP-Cy 5.5-labeled anti-CD8 and APC-labeled anti-CD25 (clone PC61) mAb, permeabilized and finally, stained with PE-labeled anti-Foxp3 mAb (eBioscience, SanDiego, CA) according to the manufacturer's instructions. In all experiments, cells were analyzed on a BD FacsCalibur ${ }^{\oplus}$.

\section{Intracellular cytokine measurement}

Single cell suspensions of splenocytes from naïve and RMA-challenged mice were restimulated in vitro with mitomycin-c treated RMA cells $[37,38]$. For intracellular cytokine measurement, day-5-blasts were challenged in vitro with RMA or EL4G- cells (1:1 ratio), or phorbol 12myristate 13-acete (PMA)/ionomycin, and stained with FITC-labeled anti-CD44, PE-labelled anti-CD4, PerCP-Cy 5.5-labeled anti-CD8, and APC-labeled anti-IFN- $\gamma \mathrm{mAb}$ as previously described [43].

\section{$C D I / b^{+}$cell purification and in vitro functional assays}

$\mathrm{CD} 11 \mathrm{~b}^{+}$cells purification was performed with mouse CD11b MicroBeads (Miltenyi Biotec, Bergisch Gladbach, Germany) following the manufacturer's instructions. Purity of the cell population was evaluated by flow cytometry and exceeded $90 \%$. BALB/c splenocytes $\left(6 \times 10^{5}\right.$ cells/ well) were stimulated in wells that had been coated with $3 \mu \mathrm{g} / \mathrm{ml}$ anti CD3 and $2 \mu \mathrm{g} / \mathrm{ml}$ anti-CD28 mAb, or alternatively, with an equal number of $\gamma$-irradiated C57BL $/ 6$ splenocytes. Purified splenic CD11 $\mathrm{b}^{+}$cells were added to the culture so as to constitute $20 \%$ of the total cells. After 
3 days of incubation, cultures were pulsed with ${ }^{3} \mathrm{H}-\mathrm{Thymi}$ dine $(1 \mu \mathrm{Ci} /$ well; Amersham Corp., Milan, Italy) for the last $18 \mathrm{~h}$. The incorporation of ${ }^{3} \mathrm{H}$-Thymidine by proliferating $\mathrm{T}$ cells (triplicate cultures) was measured by scintillation counting. Alternatively, CD11 b ${ }^{+}$cells were assessed for enzymatic activity by QuantiChrom ${ }^{\mathrm{TM}}$ Arginase Assay Kit (BioAssay Systems, Hayward, CA) following manufacturer's instructions. Results were normalized to $10^{6}$ cells.

\section{Statistical analyses}

Statistical analyses were performed using the Student's T test. Values were considered statically significant for $\mathrm{p}<$ 0.05 .

\section{Authors' contributions}

$\mathrm{MB}$ drafted the manuscript, all authors contributed to the revision. GC, NR, MF and MG performed experiments. $\mathrm{MB}$ and $\mathrm{GC}$ were involved in conception and design of the study. All authors read and approved the final manuscript.

\section{Acknowledgements}

The work was partially supported by grants from Ministero della Salute, Ministero dell'Università e della Ricerca, and Associazione Italiana per la Ricerca sul Cancro. GC has been awarded a scholarship initially from Sovvenzione Globale Ingenio, Regione Lombardia, and subsequently form the American-Italian Cancer Foundation. We thank M.P. Protti (Istituto Scientifico San Raffaele, Milan, Italy) for helpful discussions and critical comments on the manuscript.

\section{References}

I. Mellor AL, Munn DH: Creating immune privilege: active local suppression that benefits friends, but protects foes. Nat Rev Immunol 2008, 8:74-80.

2. Rabinovich GA, Gabrilovich D, Sotomayor EM: Immunosuppressive Strategies that are Mediated by Tumor Cells. Annu Rev Immunol 2007, 25:267-96.

3. Sakaguchi S: Naturally arising Foxp3-expressing CD25+CD4+ regulatory $\mathbf{T}$ cells in immunological tolerance to self and non-self. Nat Immunol 2005, 6:345-52.

4. Curiel TJ: Tregs and rethinking cancer immunotherapy. J Clin Invest 2007, I | 7: I | 67-74.

5. Gabrilovich DI, Bronte V, Chen SH, Colombo MP, Ochoa A, OstrandRosenberg S, Schreiber $\mathrm{H}$ : The terminology issue for myeloidderived suppressor cells. Cancer Res 2007, 67:425. author reply 426

6. Talmadge JE: Pathways mediating the expansion and immunosuppressive activity of myeloid-derived suppressor cells and their relevance to cancer therapy. Clin Cancer Res 2007, 1 3:5243-8.

7. Serafini P, De Santo C, Marigo I, Cingarlini S, Dolcetti L, Gallina G, Zanovello $\mathrm{P}$, Bronte V: Derangement of immune responses by myeloid suppressor cells. Cancer Immunol Immunother 2004, 53:64-72.

8. Sica A, Bronte V: Altered macrophage differentiation and immune dysfunction in tumor development. J Clin Invest 2007, I I 7: I I55-66.

9. Leenen PJ, de Bruijn MF, Voerman JS, Campbell PA, van Ewijk W: Markers of mouse macrophage development detected by monoclonal antibodies. J Immunol Methods I994, I 74:5-19.

10. Gallina G, Dolcetti L, Serafini P, De Santo C, Marigo I, Colombo MP, Basso G, Brombacher F, Borrello I, Zanovello P, et al.: Tumors induce a subset of inflammatory monocytes with immunosuppressive activity on CD8+ T cells. J Clin Invest 2006, I 1 6:2777-90.
II. Yang R, Cai Z, Zhang Y, Yutzy WHt, Roby KF, Roden RB: CD80 in immune suppression by mouse ovarian carcinoma-associated Gr-I+CD I l b+ myeloid cells. Cancer Res 2006, 66:6807-I5.

12. Huang B, Pan PY, Li Q, Sato Al, Levy DE, Bromberg J, Divino CM, Chen $\mathrm{SH}$ : Gr-I+CDII5+ immature myeloid suppressor cells mediate the development of tumor-induced $\mathbf{T}$ regulatory cells and T-cell anergy in tumor-bearing host. Cancer Res 2006 , 66: || $23-3 \mid$.

13. Filipazzi P, Valenti R, Huber V, Pilla L, Canese P, lero M, Castelli C, Mariani L, Parmiani G, Rivoltini L: Identification of a new subset of myeloid suppressor cells in peripheral blood of melanoma patients with modulation by a granulocyte-macrophage colony-stimulation factor-based antitumor vaccine. J Clin Oncol 2007, 25:2546-53.

14. Bronte V, Zanovello P: Regulation of immune responses by Larginine metabolism. Nat Rev Immunol 2005, 5:64I-54.

15. Mazzoni A, Bronte V, Visintin A, Spitzer JH, Apolloni E, Serafini P, Zanovello $\mathrm{P}$, Segal DM: Myeloid suppressor lines inhibit $\mathbf{T}$ cell responses by an NO-dependent mechanism. J Immunol 2002, 1 68:689-95

16. Fukumura $D$, Kashiwagi $S$, Jain RK: The role of nitric oxide in tumour progression. Nat Rev Cancer 2006, 6:521-34.

17. Nagaraj S, Gupta K, Pisarev V, Kinarsky L, Sherman S, Kang L, Herber $\mathrm{DL}$, Schneck J, Gabrilovich DI: Altered recognition of antigen is a mechanism of CD8+ $\mathbf{T}$ cell tolerance in cancer. Nat Med 2007, 1 3:828-35

18. Muller AJ, Scherle PA: Targeting the mechanisms of tumoral immune tolerance with small-molecule inhibitors. Nat Rev Cancer 2006, 6:613-25

19. Bronte V, Kasic T, Gri G, Gallana K, Borsellino G, Marigo I, Battistini L, lafrate M, Prayer-Galetti T, Pagano F, et al.: Boosting antitumor responses of $\mathrm{T}$ lymphocytes infiltrating human prostate cancers. J Exp Med 2005, 20 I: I 257-68.

20. Orucevic A, Bechberger J, Green AM, Shapiro RA, Billiar TR, Lala PK: Nitric-oxide production by murine mammary adenocarcinoma cells promotes tumor-cell invasiveness. Int J Cancer |999, 8 |:889-96.

21. Cahlin C, Gelin J, Delbro D, Lonnroth C, Doi C, Lundholm K: Effect of cyclooxygenase and nitric oxide synthase inhibitors on tumor growth in mouse tumor models with and without cancer cachexia related to prostanoids. Cancer Res 2000, 60:1742-9.

22. Qiu H, Orr FW, Jensen D, Wang HH, Mclntosh AR, Hasinoff BB, Nance DM, Pylypas S, Qi K, Song C, et al.: Arrest of B I6 melanoma cells in the mouse pulmonary microcirculation induces endothelial nitric oxide synthase-dependent nitric oxide release that is cytotoxic to the tumor cells. Am J Pathol 2003, 162:403-12.

23. Serafini P, Meckel K, Kelso M, Noonan K, Califano J, Koch W, Dolcetti L, Bronte V, Borrello I: Phosphodiesterase-5 inhibition augments endogenous antitumor immunity by reducing myeloid-derived suppressor cell function. J Exp Med 2006, 203:2691-702.

24. Bronte V, Serafini P, De Santo C, Marigo I, Tosello V, Mazzoni A, Segal DM, Staib C, Lowel M, Sutter G, et al.: IL-4-induced arginase I suppresses alloreactive $\mathbf{T}$ cells in tumor-bearing mice. Immunol 2003, 170:270-8.

25. Griswold DP, Corbett TH: A colon tumor model for anticancer agent evaluation. Cancer 1975, 36:244I-4.

26. Bronte V, Apolloni E, Cabrelle A, Ronca R, Serafini P, Zamboni P, Restifo NP, Zanovello P: Identification of a CDI Ib(+)/Gr-I(+)/ CD3I(+) myeloid progenitor capable of activating or suppressing CD8(+) T cells. Blood 2000, 96:3838-46.

27. Gordon S, Taylor PR: Monocyte and macrophage heterogeneity. Nat Rev Immunol 2005, 5:953-64.

28. Kusmartsev S, Gabrilovich DI: STATI signaling regulates tumorassociated macrophage-mediated T cell deletion. J Immunol 2005, I 74:4880-9|

29. Ljunggren HG, Karre K: Host resistance directed selectively against H-2-deficient lymphoma variants. Analysis of the mechanism. J Exp Med 1985, I 62:1745-59.

30. Bissell MJ, Radisky D: Putting tumours in context. Nat Rev Cancer 200I, I:46-54.

31. Bronte V, Serafini P, Mazzoni A, Segal DM, Zanovello P: L-arginine metabolism in myeloid cells controls T-lymphocyte functions. Trends Immunol 2003, 24:302-6. 
32. Zatz R, Baylis $C$ : Chronic nitric oxide inhibition model six years on. Hypertension 1998, 32:958-64.

33. Baylis C, Mitruka B, Deng A: Chronic blockade of nitric oxide synthesis in the rat produces systemic hypertension and glomerular damage. J Clin Invest 1992, 90:278-81.

34. Reisser D, Onier-Cherix N, Jeannin JF: Arginase activity is inhibited by L-NAME, both in vitro and in vivo. J Enzyme Inhib Med Chem 2002, I 7:267-70.

35. Martin-Fontecha A, Sebastiani S, Hopken UE, Uguccioni M, Lipp M, Lanzavecchia A, Sallusto F: Regulation of dendritic cell migration to the draining lymph node: impact on T lymphocyte traffic and priming. J Exp Med 2003, I98:6I5-2I.

36. Degl'Innocenti E, Grioni M, Capuano G, Jachetti E, Freschi M, Bertilaccio MT, Hess-Michelini R, Doglioni C, Bellone M: Peripheral T. cell tolerance associated with prostate cancer is independent from CD4+CD25+ regulatory T cells. Cancer Res 2008, 68:292-300.

37. lezzi G, Protti MP, Rugarli C, Bellone M: B7.I expression on tumor cells circumvents the need of professional antigen presentation for in vitro propagation of cytotoxic $\mathbf{T}$ cell lines. Cancer Res 1996, 56: II-5.

38. lezzi G, Rivolta L, Ronchetti A, Martin-Fontecha A, Rosato A, Protti MP, Sabbadini MG, Bellone M: The immunogenicity of experimental tumors is strongly biased by the expression of dominant viral cytotoxic T-lymphocyte epitopes. Cancer Res 1997, 57:2564-8.

39. Kusmartsev S, Cheng F, Yu B, Nefedova Y, Sotomayor E, Lush R, Gabrilovich D: All-trans-retinoic acid eliminates immature myeloid cells from tumor-bearing mice and improves the effect of vaccination. Cancer Res 2003, 63:444I-9.

40. De Santo C, Serafini P, Marigo I, Dolcetti L, Bolla M, Del Soldato P, Melani C, Guiducci C, Colombo MP, lezzi M, et al.: Nitroaspirin corrects immune dysfunction in tumor-bearing hosts and promotes tumor eradication by cancer vaccination. Proc Nat Acad Sci USA 2005, 102:4185-90.

41. Gorer PA: Studies in antibody response of mice to tumour inoculation. $\mathrm{Br} /$ Cancer 1950, 4:372-9.

42. Bertilaccio MT, Grioni M, Sutherland BW, Degl'Innocenti E, Freschi M, Jachetti E, Greenberg NM, Corti A, Bellone M: Vasculature-targeted tumor necrosis factor-alpha increases the therapeutic index of doxorubicin against prostate cancer. Prostate 2008, 68: $1105-15$

43. Camporeale A, Boni A, lezzi G, Degl'Innocenti E, Grioni M, Mondino $A$, Bellone $M$ : Critical impact of the kinetics of dendritic cells activation on the in vivo induction of tumor-specific $\mathbf{T}$ lymphocytes. Cancer Res 2003, 63:3688-94.
Publish with Bio Med Central and every scientist can read your work free of charge

"BioMed Central will be the most significant development for disseminating the results of biomedical research in our lifetime. "

Sir Paul Nurse, Cancer Research UK

Your research papers will be:

- available free of charge to the entire biomedical community

- peer reviewed and published immediately upon acceptance

- cited in PubMed and archived on PubMed Central

- yours - you keep the copyright
BioMedcentral 